\title{
PENGARUH MODEL COOPERATIVE LEARNING TERHADAP SIKAP KERJASAMA DAN HASIL BELAJAR SEPAKBOLA
}

\author{
Sopian Eka Pratama' ${ }^{1}$ Oman Hadiana ${ }^{2}$ \\ STKIP Muhammadiyah Kuningan \\ email: oman hadiana@gmail.com
}

\begin{abstract}
Abstrak
Tujuan penelitian ini untuk mengetahui pengaruh model cooperative learning terhadap sikap kerjasama dan hasil belajar sepakbola pada siswa kelas VIII di SMP Negeri 7 Kuningan. Metode penelitian ini adalah metode eksperimen dengan menggunakan design penelitian one grup pretest-posttest design.Populasi dalam penelitian ini seluruh siswa kelas VIII di SMP Negeri 7 Kuningan berjumlah 365, sedangkan sampel sebanyak 40 siswa. Teknik pengambilan sampel menggunakan teknik cluster random sampling yaitu mengambil secara acak dikarenakan untuk menghindari terjadinya pemilihan sampel yang dispesialkan atau ditunjuk secara khusus, agar kesempatan populasi untuk menjadi sampel sama besar yang berjumlah 40 siswa. Instrumen yang digunakan dalam penelitian, angket sikap kerjasama dan tes passing dan stopping sepakbola. Hasil penelitian ini untuk sikap kerjasama post-test $>$ pre-test $=102,18>$ 101,60, artinya terjadi pengaruh sikap kerjasama sebelum dan sesudah menggunakan model cooperative learning dengan selisih 0,58. Selanjutnya hasil belajar post-test > pre-test $=13,13$ $>$ 10,40, artinya terjadi pengaruh hasil belajar sepakbola sebelum dan sesudah menggunakan model cooperative learning dengan selisih 2,73
\end{abstract}

Kata Kunci: Model, Cooperative learning, Kerjasama, Hasil Belajar, Sepakbola.

\begin{abstract}
The purpose of this study was to determine the effect of cooperative learning models on the attitude of cooperation and learning outcomes of football in class VIII students at SMP Negeri 7 Kuningan. The method of this research is the experimental method using one group pretestposttest design research design. The population in this study all class VIII students at SMP Negeri 7 Kuningan totaled 365, while the sample was 40 students. The sampling technique uses cluster random sampling technique that is taking randomly because to avoid the selection of samples that are specified or specifically designated, so that the population opportunity to be a sample is as large as 40 students. The instrument used in the study, the attitude questionnaire of cooperation and passing and stopping football tests. The results of this study for post-test cooperation attitude> pre-test $=102.18>101.60$, meaning that there is an influence of cooperative attitude before and after using the cooperative learning model with a difference of 0.58. Furthermore, the post-test $>$ pre-test $=13,13>10,40$ learning outcomes, meaning that there is an influence on the results of football learning before and after using the cooperative learning model with a difference of 2.73 .
\end{abstract}

Keywords: Model, Cooperative learning, Collaboration, Learning Outcomes, Football. 
PENDAHULUAN

Salah satu olahraga permainan beregu yang diajarkan di SMP adalah sepakbola. Sepakbola merupakan cabang olahraga yang sangat banyak disukai oleh siswa ataupun oleh masyarakat khususnya di sekolah, hal ini dapat dilihat pada waktu jam istirahat banyak siswa yang bermain sepakbola. Beberapa teknik dasar yang perlu dimiliki pemain sepakbola adalah menendang (kicking), menghentikan atau mengontrol (stopping), menggiring (dribbling) dan menyundul (heading).

Sesuai dengan SK-KD, dalam pemetaan materi pembelajaran Pendidikan jasmani di SMP Negeri 7 Kuningan, permainan sepakbola wajib pada siswa kelas VIII semester 2. Permainan sepakbola merupakan aktivitas kelompok, kemampuan suatu regu sepakbola ditentukan oleh keterampilan teknik dasar yang dimiliki oleh setiap anggotanya dalam melakukan fungsinya masing-masing. Pengetahuan tentang teknik dasar sepakbola tersebut penting diberikan kepada siswa agar siswa mempunyai pengetahuan yang mendasar tentang sepakbola, mampu mengembangkan bakat-bakat dalam bermain sepakbola, mengerti arti pentingnya belajar keterampilan teknik dasar sepakbola, memahami nilai-nilai yang terkandung didalamnya, serta membentuk watak dan sifat seseorang saat permainan berlangsung.
Berdasarkan hasil observasi yang dilakukan di SMP Negeri 7 Kuningan, diketahui bahwa pembelajaran pendidikan jasmani terutama sepakbola di SMP Negeri 7 Kuningan masih bergantung pada penjelasan guru. Pola pembelajarannya selama ini, guru masih menggunakan model pembelajaran dimana guru lebih berperan aktif dalam mengajar, sehingga siswa hanya berperan sebagai penerima informasi saja atau kurang aktif dalam mengikuti proses pembelajaran dan siswa melakukan pembelajaran secara individu sehingga terjadi ketidakseimbangan antara siswa yang lebih terampil atau berbakat dengan siswa yang kurang terampil, serta suasana pembelajaran yang kurang kondusif. Kebanyakan siswa lebih mementingkan memasukan bola kegawang lawan secara sendiri-sendiri dari pada harus bekerjasama dengan teman satu timnya.

Teknik dasar passing dalam permainan sepakbola juga kurang baik, sebagi contoh pada saat akan memberikan bola ke teman satu timnya, posisi tidak mendukung untuk melakukan passing tetapi tetap memaksakan untuk memberikan bola ketemannya dan hasilnya bola mengarah ke lawan bukan ke temannya. Hal tersebut menyebabkan siswa yang kurang terampil menjadi pasif dalam pembelajaran, sehingga terjadi kesenjangan antara siswa yang yang lebih atau berbakat dengan siswa yang kurang, serta suasana pembelajaran yang kurang kondusif. Hal ini 
menyebabkan tidak tercapainya tujuan pembelajaran pendidikan jasmani khususnya sepakbola. Dampak yang terjadi dengan adanya masalah ini adalah kerjasama dan hasil belajar siswa khususnya dalam pembelajaran passing dalam sepakbola kurang maksimal.

Dengan adanya permasalahan ini, maka dibutuhkan suatu model pembelajaran yang menciptakan cara belajar siswa aktif sesuai dengan keadaan dan kebutuhannya serta pembelajaran berpusat pada siswa, sehingga potensi dan kemampuan yang dimiliki siswa akan berkembang secara maksimal serta tujuan pembelajaran pendidikan jasmani dan tujuan pendidikan nasional akan tercapai dengan baik. Salah satunya adalah dengan menerapkan model pembelajaran cooperative learning tipe Student Teams Achievement Division (STAD). Model pembelajaran cooperative learning merupakan salah satu model pembelajaran yang mendukung pembelajaran kontekstual. Sistem pembelajaran cooperative learning dapat didefenisikan sebagai sistem kerja atau belajar kelompok yang terstruktur. Menurut Tite dkk., (2013: 82), Student Teams Achievement Division (STAD) atau pembagian pencapaian tim siswa. Dalam STAD para siswa dibagi dalam tim belajar yang terdiri dari empat orang dengan tingkat kemampuan, jenis kelamin, dan latar belakang etnik yang berbeda. Gagasan utama dari STAD adalah untuk memotivasi siswa agar dapat saling mendukung dan membantu satu sama lain dalam menguasai kemampuan yang diajarkan oleh guru.

\section{METODE}

Metode yang digunakan dalam penelitian ini menggunakan metode preeksperimen dengan desain one-group pretest-posttest design. Sugiyono (2015:110). Populasi dalam penelitian ini adalah siswa kelas VIII di SMP Negeri 7 Kuningan yang berjumlah 365 siswa. Teknik sampling yang digunakan dalam penelitian ini adalah cluster random sampling, Sugiyono (2015:122). Sampel penelitian kelas VIII B berjumlah 40 siswa. Instrumen untuk mengukur kerjasama menggunakan angket berupa kuisioner dengan skala likert yang telah teruji validitas dan reliabilitasnya. Sedangkan instrumen untuk mengukur hasil belajar passing dalam sepakbola menggunakan tes passing-stoping, Nurhasan (2007). Analisis data yang digunakan uji validitas angket sikap kerjasama bantuan software SPSS versi 21, uji reabilitas angket sikap kerjasama bantuan software SPSS versi 21, uji normalitas Shapiro-Wilk Test dengan taraf signifikansi $5 \%$ atau 0,05 . uji homogenitas Shapiro-Wilk Test dengan taraf signifikansi $5 \%$ atau 0,05 . uji hipotesis menggunakan Uji-t sampel berpasangan (Paired Sample t-test). 


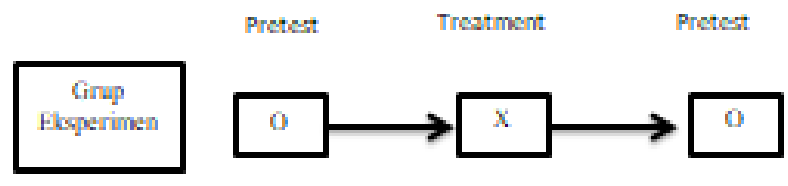

Gambar 1 Rancangan Penelitian

\section{HASIL PENELITIAN}

Deskripsi data yang akan disajikan dari hasil penelitian ini adalah untuk memberikan gambaran data yang diperoleh di lapangan. Data yang disajikan merupakan data mentah yang diolah menggunakan teknik statistik nonparametris.

\begin{tabular}{|l|l|c|c|c|c|c|}
\hline Kelompok & $\begin{array}{c}\text { Priode } \\
\text { Tes }\end{array}$ & $\begin{array}{c}\text { Rata- } \\
\text { Rata }\end{array}$ & Sesilisih & $\begin{array}{c}\text { Simpangan } \\
\text { Baku }\end{array}$ & $\begin{array}{c}\text { Nilai } \\
\text { Minimum }\end{array}$ & $\begin{array}{c}\text { Nilai } \\
\text { Maksimum }\end{array}$ \\
\hline \multirow{2}{*}{$\begin{array}{l}\text { Sikap } \\
\text { Kerjasama }\end{array}$} & Awal & 101,60 & \multirow{2}{*}{0,58} & 9,787 & 81 & 120 \\
\cline { 2 - 6 } & Akhir & 102,18 & & 11,193 & 73 & 123 \\
\hline \multirow{2}{*}{$\begin{array}{l}\text { Hasil } \\
\text { Belajar }\end{array}$} & $\begin{array}{l}\text { Tes } \\
\text { Awal }\end{array}$ & 10,40 & \multirow{2}{*}{2,73} & 2,036 & 7 & 14 \\
\cline { 2 - 6 } & $\begin{array}{l}\text { Tes } \\
\text { Akhir }\end{array}$ & 13,13 & & 1,814 & 9 & 16 \\
\hline
\end{tabular}

Tabel 1. Perhitungan Rata-Rata,Selisih, Simpangan Baku, Minumum dan Maksimum Pre-Pos Test Sikap Kerjasama dan Hasil Belajar

Dari data sikap kerjasama yaitu dengan menggunakan angket, awal dan akhir dapat dilihat rata-rata awal $=101,60$, rata-rata akhir $=102,18$, dengan selisih antara awal dan akhir $=0,58$. Simpangan baku awal $=$ 9,787 dan akhir 11,193. Nilai minimum awal $=81$ dan nilai minimum akhir $=73$. maksimum awal $=120$ dan nilai akhir $=$ 123. Dari data hasil belajar sepakbola menggunakan tes passing, dapat dilihat rata-rata tes awal $=10,40$, rata-rata tes akhir $=13,13$, dengan selisih antara tes awal dan tes akhir $=2,73$. Simpangan baku tes awal $=2,036$ dan tes akhir 1,814. Nilai minimum tes awal $=7$ dan nilai minimum tes akhir $=$
9. Maksimum tes awal $=14$ dan nilai tes akhir $=16$.

Dari data diatas dapat dideskripsikan terdapat perbedaan sebelum dan sesudah menggunakan model cooperative learning tipe STAD terhadap sikap kerjasama dalam permainan sepakbola di SMP Negeri 7 Kuningan, ini dapat dilihat dari hasil post-test > pre-test yaitu 102,18 > 101,60 dengan selisih 0,58. Dengan demikian pembelajaran model cooperative learning tipe STAD dapat meningkatkan kerjasama dalam permainan sepakbola. 
Dari data diatas dapat dideskripsikan terdapat perbedaan sebelum dan sesudah menggunakan model cooperative learning tipe STAD terhadap sikap kerjasama dalam permainan sepakbola di SMP Negeri 7 Kuningan, ini dapat dilihat dari hasil posttest > pre-test yaitu 102,18>101,60 dengan selisih 0,58. Dengan demikian pembelajaran model cooperative learning tipe STAD dapat meningkatkan kerjasama dalam permainan sepakbola. Hal ini sesuai dengan yang diungkapkan oleh:

Tite Juliantine, dkk (2013: 75-76), pembelajaran dengan model kooperatif dapat membentuk pribadi yang terbuka dan menerima perbedaan yang terjadi karena dalam pembelajaran kooperatif, kerjasama yang dilakukan tidak memandang perbedaan ras, agama ataupun status sosial. dengan demikian para siswa memiliki sikap saling mengerti dan menerima perbedaan satu dengan yang lainnya. Sehingga dapat dinyatakan bahwa pembelajaran dengan model kooperatif telah meningkatkan ketertarikan interpersonal diantara siswa, baik pada saat pembelajaran disekolah atau diluar sekolah.

Selanjutnya terdapat perbedaan sebelum dan sesudah menggunakan model cooperative learning tipe STAD terhadap hasil belajar teknik dasar passing dalam permainan sepakbola di SMP Negeri 7 Kuningan. ini dapat dilihat dari hasil posttest $>$ pre-test yaitu 13,13>10,40 dengan selisih 2,73. Dengan demikian model pemebelajaran menggunakan cooperative learning tipe STAD dapat meningkatkan hasil belajar passing dalam permainan sepakbola. Hal tersebut sesuai dengan yang diungkapkan oleh:

Tite Juliantine, dkk (2013: 82), gagasan utama dari STAD adalah untuk memotivasi agar dapat saling mendukung dan membantu satu sama lain dalam menguasi kemampuan yang diajarkan oleh guru. Mereka boleh berkerja berpasangan dan membandingkan jawaban masingmasing, mendiskusikan semua penemuan, dan saling membantu satu sama lain jika ada yang salah dalam memahami.

\section{SIMPULAN}

Berdasarkan hasil pengolahan dan hasil analisis data, maka kesimpulan dalam penelitian ini adalah "Model pembelajaran cooperative learning tipe STAD dapat meningkatkan kerjasama dan hasil belajar sepakbola di SMP Negeri 7 Kuningan".

\section{DAFTAR PUSTAKA}

C. Trihendradi. 2010. Step by Step SPSS 18

Analisis Data Statistik.Yogyakarta: C.V. ANDI

Huda, Miftahul. 2011. Cooperative Learning. Yogyakarta: Pustaka Pelajar.

Husdarta. 2011. Manajemen Pendidikan Jasmani. Bandung: ALFABETA.

Nuh, Mohammad. 2014. Pendidikan jasmani olahraga dan kesehatan.Jakarta: KEMDIKBUD. 
Nurhasan. Hasanudin. 2007. Modul Tes dan

Pengukuran Keolahragaan.Bandung : Universitas Pendidikan Olahraga.

Rahmani, Mikanda.2014. Buku Super Lengkap Olahraga.Jakarta Timur: Dunia Cerdas.

Sugiyono. 2015. Metode penelitian Pendidikan. Bandung : Alfabeta.
Sudjana, Nana. 2013. Penilaian Hasil Proses Belajar Mengajar. Bandung: PT. Remaja Rosdakarya.

Suyono, Haryanto. 2015. Belajar dan Pembelajaran. Bandung: PT. Remaja Rosdakarya.

Tite, ddk. 2013. Model-model Pembelajaran Dalam Pendidikan Jasmani. Bandung: Universitas Pendidikan Indonesia. 